
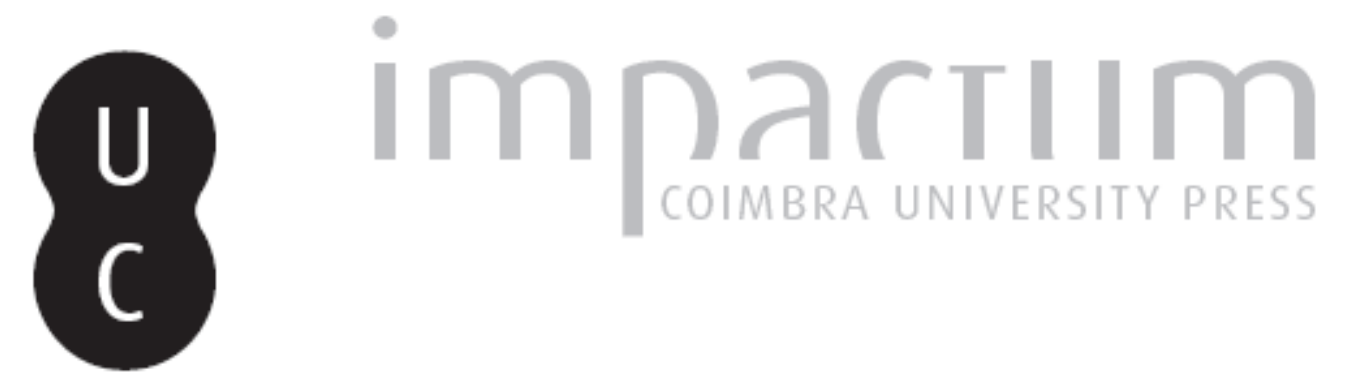

\title{
O exílio liberal português de 1828-1832, um fenómeno multidimensional: práticas sociais e culturais
}

\author{
Autor(es): $\quad$ Faria, Fábio Alexandre
}

Publicado por: Imprensa da Universidade de Coimbra

URL persistente:

URI:http://hdl.handle.net/10316.2/40962

DOI:

DOI:https://doi.org/10.14195/1645-2259_16_12

Accessed : $\quad$ 26-Apr-2023 11:43:11

A navegação consulta e descarregamento dos títulos inseridos nas Bibliotecas Digitais UC Digitalis, UC Pombalina e UC Impactum, pressupõem a aceitação plena e sem reservas dos Termos e Condições de Uso destas Bibliotecas Digitais, disponíveis em https://digitalis.uc.pt/pt-pt/termos.

Conforme exposto nos referidos Termos e Condições de Uso, o descarregamento de títulos de acesso restrito requer uma licença válida de autorização devendo o utilizador aceder ao(s) documento(s) a partir de um endereço de IP da instituição detentora da supramencionada licença.

Ao utilizador é apenas permitido o descarregamento para uso pessoal, pelo que o emprego do(s) título(s) descarregado(s) para outro fim, designadamente comercial, carece de autorização do respetivo autor ou editor da obra.

Na medida em que todas as obras da UC Digitalis se encontram protegidas pelo Código do Direito de Autor e Direitos Conexos e demais legislação aplicável, toda a cópia, parcial ou total, deste documento, nos casos em que é legalmente admitida, deverá conter ou fazer-se acompanhar por este aviso.

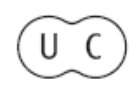




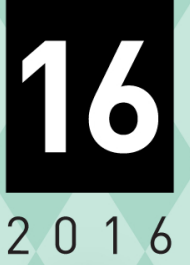

\section{Revista \\ de História \\ da Sociedade \\ e da \\ Cultura}




\title{
O exílio liberal português de 1828-1832, um fenómeno multidimensional: práticas sociais e culturais ${ }^{1}$
}

\section{The Portuguese liberal exile from 1828-1832, a multidimensional phenomenon: social and cultural practices}

\author{
FÁbio AleXANDre FARIA \\ ISCTE-IUL \\ fabiofaria19@hotmail.com
}

Texto recebido em / Text submitted on: 07.04.2016

Texto aprovado em / Text approved on: 04.07.2016

Resumo: No contexto revolucionário europeu dos inícios do século XIX, fortemente instável, após D. Miguel regressar a Portugal do seu exílio em Viena e tomar o trono português, em 1828, milhares de liberais, fugindo da perseguição absolutista, abandonaram o país com destino ao maior exílio português de Oitocentos. Apesar de se constituir inicialmente como um fenómeno inteiramente político, o exílio liberal português de 1828-1832, assumiu-se como uma experiência bastante mais ampla, englobando uma diversidade de dimensões. Nunca perdendo a sua componente política, vincadamente presente, foi também um fenómeno de elevada importância social, cultural e intelectual, com visíveis repercussões após a vitória liberal na guerra civil de 1832-1834. Explora-se, neste artigo, cada uma dessas dimensões e demonstra-se que este exílio, apesar das inúmeras dificuldades que a ele estiveram associadas, contribuiu para o desenvolvimento cultural e intelectual de Portugal. Assim, dar-se-á particular atenção às práticas sociais e culturais que marcaram o quotidiano da elite liberal exilada.

Palavras-chave: exílio político, exilados, vida quotidiana, circulações internacionais, Inglaterra.

Abstract: In the European revolutionary context of the early $19^{\text {th }}$ century, strongly unstable, after Don Miguel returned to Portugal from his exile in Vienna and took the Portuguese throne in 1828, thousands of liberals left the country fleeing the absolutist persecution and started the largest Portuguese exile of the $19^{\text {th }}$ century. Even though it was originally an entirely political phenomenon, the Portuguese liberal exile from 1828-1832 was seen as a much more extensive experience, encompassing a diversity of dimensions. Never losing its strong political component, it was also a phenomenon of high social, cultural

1 Este artigo tem por base a minha dissertação de mestrado, intitulada Circulações Internacionais e Liberalismo. O Exílio Liberal Português, 1828-1832, recentemente defendida no ISCTE - IUL. 
and intellectual importance, with visible repercussions after the liberal victory in the Portuguese civil war of 1832-1834. This paper analyses each of these dimensions and shows that the exile, despite all the difficulties associated, has contributed to the cultural and intellectual development of Portugal. Particular attention will be given to social and political practices that marked the everyday life of the exiled liberal elite.

Keywords: political exile, exiles, everyday life, international circulations, England.

\section{Introdução}

No início do século XIX, Portugal, atingido pelo desejo expansionista de Napoleão Bonaparte, imperador francês desde 1804, viu o seu território ser invadido três vezes pelas tropas francesas. Uma das principais consequências destas invasões consistiu na fuga de D. João VI e da restante família real para o Brasil e na consequente recusa em regressar a Portugal após a vitória definitiva contra as forças napoleónicas. Esta situação, a que acrescia o domínio britânico em Portugal, agravou o descontentamento português e, a 24 de agosto de 1820, teve lugar a revolução liberal. Esta primeira experiência liberal duraria apenas três anos, mas estaria na origem de uma luta política e ideológica, à semelhança do que aconteceu um pouco por toda a Europa, entre liberais e absolutistas até 1834 , ano do triunfo definitivo dos primeiros sobre os segundos.

A subida ao poder de D. Miguel, em julho de 1828, teve como efeito imediato a saída em massa de liberais de Portugal com destino ao estrangeiro, sobretudo Inglaterra e França, quer anónimos, quer personalidades que já vinham a ter algum destaque na cena política portuguesa ao longo da década de 1820. Este exílio, que para a grande parte dos seus intervenientes terminou em 1832, com o desembarque das tropas liberais comandadas por D. Pedro no Porto, em julho, e com o consequente início da guerra civil (1832-1834), foi o mais importante a ter lugar em Portugal ao longo do século XIX. Foi um fenómeno que se inseriu num contexto internacional muito próprio, numa época em que um grande número de países europeus enfrentava o problema da emigração forçada, resultado de muitos governos quererem fazer prevalecer a velha ordem do Antigo Regime, abalada pela Revolução Francesa de 1789.

Não obstante o facto de o principal motivo que levou os liberais a abandonar o país ser político, o exílio liberal português de 1828-1832 revestiu-se de várias outras dimensões que levaram este fenómeno a assemelhar-se a outros exílios europeus deste período. Este artigo centra-se, portanto, na aná- 
lise dessas várias dimensões, procurando-se demonstrar que o exílio liberal português de 1828-1832 não foi um fenómeno exclusivamente político e que contribuiu para o desenvolvimento intelectual e cultural de Portugal após 1834. Para tal, é dada especial atenção às práticas sociais e culturais quotidianas dos exilados durante a sua estadia no estrangeiro.

\section{O exílio liberal português em Plymouth}

Em consequência da tomada do poder por D. Miguel em 1828, o descontentamento liberal fez-se manifestar e sucederam-se os episódios de resistência contra os absolutistas. $\mathrm{O}$ episódio de resistência ao miguelismo que esteve mais diretamente ligado ao início do exílio liberal de 1828 teve lugar a meio desse ano e ficou conhecido por Belfastada. O nome dado a esta insurreição encontra-se relacionado com o barco Belfast, fretado em Inglaterra, com o objetivo de recolher parte dos revoltosos no Porto. Nesta cidade, em maio de 1828, havia sido constituída uma Junta de Governo Provisório, contrária a D. Miguel. Contudo, acabou destronada pelo exército miguelista, levando à fuga de milhares de revoltosos. Estiveram associados a esta revolta importantes nomes do liberalismo português, como Palmela, Saldanha e Sá da Bandeira.

Como afirma Grégoire Bron, o exílio liberal português foi constituído não só por uma elite que fazia lembrar o cosmopolitismo do século anterior, como também por cidadãos anónimos. No entanto, o grosso desta emigração liberal era formado pela classe militar (Bron 2013: 546). Plymouth foi o grande destino dos militares implicados na Belfastada. Após uma passagem atribulada por Espanha, os exilados militares desembarcaram em Inglaterra entre os finais de agosto e os inícios de setembro de $1828^{2}$.

À chegada a Inglaterra, os militares portugueses, detentores de menores posses, ficaram divididos em seis classes e agrupados num depósito que fora criado em Plymouth para esse efeito. Este depósito apresentava duras condições de vida e foi inicialmente administrado por Cândido José Xavier, político e militar que acompanhara Palmela no Belfast, mas que não recolhia muita simpatia entre os exilados, uma vez que havia participado nos exércitos do general Massena aquando da terceira invasão francesa em Portugal, em 1810-1811. Cândido José Xavier (mais tarde substituído pelo general Stu-

\footnotetext{
2 Para conhecer a passagem dos exilados liberais portugueses por Espanha ver Maia 1841. O autor
} afirma ter acompanhado todo o percurso por Espanha até Inglaterra. 
bbs) foi coadjuvado por Paulo Midosi (secretário) e por um negociante de apelido Carvalho (tesoureiro) (Nemésio 1946: 52).

O sustento destes emigrados era assegurado pelas quantias que Palmela, chefe da emigração liberal portuguesa, retirava do dinheiro que Portugal recebia do Brasil, na sequência do tratado de independência desta ex-colónia, assinado em 1825 (Bonifácio 2005: 15). No entanto, a não uniformidade quanto à distribuição destes subsídios tornou-se um dos principais elementos geradores de discórdia entre os exilados liberais e contribuiu para que não se alcançasse a tão necessária e desejada união entre os constitucionais para que a causa liberal triunfasse.

A divisão, que não foi do agrado dos exilados portugueses, encontrava-se feita da seguinte forma: primeira classe - oficiais generais e estado-maior; segunda classe - oficiais de primeira linha; terceira classe - oficiais de segunda linha e voluntários; quarta classe - empregados civis (magistrados, oficiais de fazenda e de justiça); quinta classe - sacerdotes, negociantes e proprietários; sexta classe - praças de primeira e segunda linhas, voluntários (académicos de Coimbra e do Porto) e criados de servir (Maia 1841: 163).

Os barracões de Plymouth eram construídos em madeira e comportavam janelas sem vidros, bancos e cadeiras ou camas. $\mathrm{O}$ chão encontrava-se revestido apenas por palha, que era trocada com uma periodicidade de quinze dias. Estes albergues tinham um custo mensal de cerca de cem libras. Contudo, o espaço disponível nesses barracões não era suficiente para acolher todos os refugiados portugueses necessitados, pelo que, de acordo com Vitorino Nemésio, terão sido alugadas quatro embarcações paradas para que os restantes emigrados pudessem dormir nos seus porões. O aluguer de cada uma destas embarcações custava cinquenta libras (Nemésio 1946: 53).

A alimentação também era diferente consoante a classe onde se encontravam os exilados. Baseava-se no fornecimento de uma ração diária composta por pão, carne e arroz, que era entregue em géneros apenas aos emigrados inseridos na sexta classe, ao passo que os restantes recebiam em dinheiro. Os oficiais militares de primeira e de segunda linhas obtinham ainda uma remuneração igual ao valor que usufruíam em Portugal, da mesma forma que era pago aos empregados civis o ordenado como se estivessem a exercer as próprias funções. Os voluntários que não eram oficiais, considerados simples soldados, gozavam de uma pensão mensal no valor de catorze shillings, enquanto médicos, proprietários e negociantes usufruíam de uma mensalidade na ordem das três libras. Assim sendo, verifica-se que os subsídios entregues aos emigrados estavam dependentes da sua atividade profissional, pelo que era essencial que estes a comprovassem, com vista a obterem as 
ditas quantias. Para tal era suficiente a sua palavra, e quando surgissem dúvidas, estas poderiam ser desfeitas através de um comprovativo assinado por outros três emigrados (Maia 1841: 164-165).

Silva Maia entendia que os grandes beneficiários da divisão do dinheiro efetuada por Palmela e por Cândido José Xavier eram os exilados que se encontravam inseridos nas quatro primeiras classes, na medida em que recebiam consideravelmente mais do que usufruíam em Portugal, visto não estarem sujeitos às despesas associadas aos seus empregos em exercício.

Não obstante as dificuldades por que passou a maioria dos emigrados em Plymouth, houve alguns liberais exilados que puderam usufruir das comodidades que a região oferecia. Passos Manuel e Passos José, inicialmente exilados em Plymouth, contaram com as quantias enviadas pela mãe, a partir do Porto, por intermédio de uma casa comercial. No exílio em Inglaterra, os irmãos Passos receberam três libras por mês, o equivalente à categoria de advogado, para além de subsídios alimentares (Pinheiro 1996: 52). Passado pouco tempo, Manuel e José abandonariam Inglaterra com destino a França, a partir de onde passariam a fazer oposição à fação política chefiada por Palmela.

Com vista a tentar resolver os atritos existentes entre os exilados portugueses, Palmela ordenou que José da Silva Carvalho fosse para Plymouth, em finais de 1828. Este, que gozava de acentuada popularidade entre os emigrados portugueses, dada a sua participação na revolução liberal de 1820, chegou a Londres em outubro de 1828 para o seu segundo exílio ${ }^{3}$.

Esta viagem de José da Silva Carvalho a Plymouth parece ter obtido os resultados pretendidos, pelo menos no entendimento deste interveniente. Em carta datada de 1 de dezembro de 1828, Silva Carvalho afirmava que as más impressões dirigidas a Palmela já tinham desaparecido e que os emigrados demonstravam ter total confiança no trabalho desenvolvido pelos ministros de D. Pedro. Na opinião de Silva Carvalho, as desconfianças relativamente a esses ministros tinham sido originadas por escritos que eram difundidos em Plymouth (Viana 1891: 18).

Em novembro de 1828 a situação dos emigrados em Inglaterra agravou-se. O governo britânico, representado por Wellington, ordenou que os exilados portugueses que se encontravam concentrados em Plymouth dispersassem por vários outros locais.

\footnotetext{
José da Silva Carvalho já havia estado exilado entre 1823, quando se iniciou a repressão absolutista à primeira experiência liberal em Portugal, e 1826, por altura da outorga da Carta Constitucional por D. Pedro, que permitiu o regresso de vários exilados liberais ao país.
} 
Para Silva Maia, a ordem de dispersão dada aos emigrados portugueses pelo governo de Wellington era concertante com as leis britânicas que proibiam a concentração de depósitos militares estrangeiro (Maia 1841: 191).

Sobre esta questão, Silva Carvalho considerava, em carta de 6 de dezembro de 1828, que os exilados portugueses, na impossibilidade de poderem ir para qualquer região do território português, deveriam dirigir-se para o Brasil, visto que "só ali poderemos achar seguros meios de voltar a vingar os direitos da nossa Rainha e os nossos", afirmando que esta ideia havia agradado aos liberais (Viana 1891: 21).

Deparando-se com esta situação, Palmela não teve outra solução que não fosse planear a saída dos exilados portugueses do país. Em carta datada de 10 de dezembro de 1828 e dirigida a José da Silva Carvalho, o diplomata português refere-se à preparação da primeira expedição de exilados portugueses com vista a saída de Inglaterra, contando, para esse efeito, com quatro embarcações disponíveis em Plymouth (Viana 1891: 23).

Segundo Silva Maia, esta primeira expedição foi composta por 604 praças de infantaria, caçadores e vários oficiais e foi comandada pelo general Saldanha. Stubbs, que, entretanto, substituíra Cândido José Xavier como responsável pelo depósito de Plymouth, ordenara a Saldanha que os navios com os emigrados portugueses se dirigissem para o Rio de Janeiro. No entanto, a expedição deveria fazer uma escala na ilha Terceira, onde daria por terminada a viagem, se assim fosse possível, caso contrário seguiria até ao Brasil (Maia 1841: 197-198).

Relativamente à saída dos emigrados portugueses de Inglaterra, José da Silva Carvalho assegurava ao visconde de Itabaiana, representante brasileiro em Inglaterra, que se fosse permitido a alguns exilados ficar na Europa em vez de ir para o Brasil, estes não queriam continuar em Inglaterra, mas sim ir para Ostende, na Bélgica (Viana 1891: 23). Observa-se assim que, não obstante a proximidade cultural com o Brasil, muitos exilados portugueses saídos de Inglaterra, preferiam continuar na Europa, preferencialmente na Bélgica, enquanto durasse o domínio absolutista em Portugal.

No início de 1829 seguiram-se outras expedições portuguesas para fora de Inglaterra. De acordo com Silva Maia, as primeiras embarcações que saíram a seguir à expedição de Saldanha, maioritariamente constituídas por militares, tiveram a mesma ordem de seguir para o Brasil, caso não pudessem desembarcar na Terceira. Os últimos navios a sair de Inglaterra receberam uma ordem diferente e, em vez de ir para a ilha açoriana, deveriam dirigir-se diretamente para o Brasil. Esta mudança de orientação terá estado relacionada com o facto de haver conhecimento de que D. Miguel mandara blo- 
quear a ilha Terceira, bem como com a convicção de que os emigrados idos de Plymouth para o arquipélago português, rondando os 2.000 indivíduos, eram suficientes para o defender dos absolutistas (Maia 1841: 198-199).

Saldanha, contrariando as ordens que recebera, dirigiu a sua expedição não para o Brasil, mas para França, onde, segundo António Viana, foi autorizado a desembarcar por influência do barão de Neuville (Viana 1891: 28). Saldanha conduziu os emigrados portugueses para Brest, onde terão gozado de um acolhimento mais cordial do que em Inglaterra.

De facto, de acordo com Silva Maia, em Paris fizeram-se representações teatrais e bailes a favor dos refugiados portugueses. No que toca à atitude do governo francês para com os exilados lusos, esta parece ter-se pautado por uma maior hospitalidade e cordialidade, se comparada com a passagem dos refugiados por Espanha e com a sua estadia em Inglaterra. Conforme relata Silva Maia, o governo francês terá disponibilizado trinta mil francos mensais para os emigrados, estipulando também três depósitos na Normandia, cada um deles com um comandante português (Maia 1841: 203-204). José da Silva Carvalho, a 3 de março de 1829, informava Palmela que, na correspondência que recebia de Brest, eram feitos grandes elogios aos franceses e constava que eram dados cento e cinquenta francos mensais a cada português, falando-se, inclusive, na existência de subscrições favoráveis aos refugiados portugueses (Viana 1891: 34).

\section{Exílio e cosmopolitismo}

Apesar de todos os emigrados portugueses, independentemente do país onde se encontrassem refugiados, terem o mesmo objetivo, - o fim do absolutismo e a reposição do regime constitucional em Portugal, - as dissensões entre os liberais continuaram a existir ao longo do período em que se encontraram exilados, motivadas, sobretudo, por questões políticas.

Na opinião de António Ferrão, existiram três grandes aspetos que desempenharam um papel fulcral na manutenção das tensões entre os exilados: o fracasso da Junta do Porto e a consequente saída do navio Belfast com destino a Londres, no início de julho de 1828; a sobrevivência dos emigrados no exílio, dificultada pela carência de condições materiais de vida, como alojamento, alimentação e vestuário; a posição de D. Pedro à frente da causa constitucional portuguesa (Ferrão 1940: 215).

Assistiu-se a uma calorosa discussão entre os exilados relativamente a todas estas questões, e particularmente sobre a última, sobretudo a partir da 
imprensa periódica desenvolvida pelos liberais no estrangeiro. Neste debate estiveram em confronto as duas fações liberais, chefiadas por Palmela e por Saldanha, sendo percetível que exilados apoiavam uma e outra fação. Assim sendo, favoráveis a Palmela, cuja política era mais moderada e de influência anglófila, encontravam-se, entre outros, Cândido José Xavier, Agostinho José Freire, José da Silva Carvalho e Rodrigo da Fonseca Magalhães. Entre os apoiantes da fação encabeçada por Saldanha, mais radical e de influência francófila, contavam-se Rodrigo Pinto Pizarro, os irmãos Passos e José Liberato Freire de Carvalho.

Saliente-se que os emigrados não tiveram sempre a mesma posição política no exílio, evoluindo consoante as circunstâncias, as ambições pessoais e o próprio desenrolar da política portuguesa. Serve de exemplo o caso de José Liberato Freire de Carvalho, que no início deste período da emigração liberal se tinha mostrado próximo de José da Silva Carvalho e de Rodrigo da Fonseca Magalhães, colaborando com estes na redação do Paquete de Portugal. Contudo, afastou-se dos principais defensores de D. Pedro e engrossou as fileiras dos seus opositores.

Porém, não foi só de política que viveu o exílio liberal português de 18281832. Apesar de ter sido um fenómeno originalmente político, isto é, ter sido motivado por questões políticas (tomada do poder por D. Miguel), os exilados liberais levaram a cabo um conjunto de atividades que foram muito para além da política, embora nunca tivessem deixado de lhe dar importância.

Um fator que foi decisivo para o desenvolvimento de algumas destas atividades por parte dos exilados prendeu-se com a necessidade de garantir o sustento enquanto se encontrassem no estrangeiro. Neste sentido, os liberais encontraram na produção escrita uma forma privilegiada para garantir esse sustento. Esta englobava a imprensa periódica, a elaboração de folhetos de propaganda política, a realização de traduções e a publicação de obras originais.

Os periódicos que iam sendo redigidos no exílio constituíram importantes elos de contacto e de comunicação. Assim, eram dos principais meios de informação e de correspondência entre os vários exilados, entre estes e os portugueses que se encontravam em Portugal e no Brasil e, ainda, entre os exilados e os estrangeiros que liam os seus periódicos. Os leitores que estavam exilados desempenhavam um importante papel na elaboração dos jornais, podendo colaborar enviando poemas, notícias, cartas e outros artigos. A imprensa do exílio constituiu um meio através do qual se desenvolveu um significativo intercâmbio cultural transnacional, uma vez que os emigrados portugueses, para além de publicarem alguns artigos em vários jornais 
estrangeiros, também usavam alguns textos que eram publicados nesses jornais e revistas para inserirem nos seus periódicos (Santos 1985: 109-110).

A partir de 1828 a prática jornalística portuguesa no estrangeiro conheceu um incremento devido ao intensificar da emigração liberal. Simultaneamente, assistiu-se também a um acentuar do desenvolvimento dos folhetos devido à sua maior maleabilidade e rapidez de circulação. Era também mais fácil passarem despercebidos à censura miguelista devido às suas reduzidas dimensões. O rápido desenvolvimento da produção de folhetos também poderá estar associado ao facto de ser mais fácil salvaguardar a identidade dos seus autores, na medida em que muitos deles eram dados a conhecer anonimamente.

Londres apresentou-se como o centro de difusão da propaganda política liberal e o que aí era publicado tinha três objetivos essenciais: primeiro, inspirar os emigrados a não perderem o fulgor revolucionário contra o absolutismo de D. Miguel; segundo, difundir o máximo possível os ideais liberais em Portugal; e terceiro, tentar demonstrar aos principais governos europeus que era possível ao liberalismo vencer as forças absolutistas, por forma a garantir, no mínimo, a neutralidade dessas potências, quando não fosse possível conseguir o seu apoio direto (Tengarrinha 2013: 452).

A imprensa periódica desenvolvida pelos emigrados liberais no exílio esteve em consonância com a divisão política existente entre estes, ou seja, muitos dos jornais publicados eram partidários de uma ou de outra fação política e, por essa razão, eram apoiantes ou opositores de D. Pedro IV.

Ainda antes de se iniciar a publicação dos que viriam a ser os principais periódicos portugueses em Londres, foram publicados dois importantes jornais em Plymouth, onde a maioria dos emigrados estava concentrada, ainda no decorrer de 1828: O Padre Malagrida ou a Tesoura: Periódico Político e Literário, redigido por José Pinto Rebelo de Carvalho, entre novembro de 1828 e abril de 1829; O Português Emigrado ou Realista Constitucional, escrito em inglês e em português e redigido por Marcos Pinto Soares Vaz Preto, entre outubro de 1828 e fevereiro de 1829. Não era ainda possível observar nestes periódicos uma preferência partidária clara relativamente a $\mathrm{D}$. Pedro.

A partir de 1829 a redação dos periódicos deixa de estar concentrada em Plymouth e passa a ter como núcleo principal a cidade de Londres, sendo aqui que a imprensa periódica passou a estar diretamente associada ao conflito político entre as duas fações liberais. Neste sentido, a imprensa periódica da emigração liberal passou a mostrar-se mais próxima ou mais afastada de D. Pedro, embora alguns jornais apresentassem uma orientação mais neutral e apelassem à conciliação entre os exilados. 
Ao lado de D. Pedro colocaram-se o Paquete de Portugal e o A Aurora. Estes dois periódicos foram dos mais influentes entre os exilados liberais e também foram os que conheceram uma maior tiragem. Apresentavam em comum o facto de terem tido como redator principal Rodrigo da Fonseca Magalhães. O Paquete de Portugal, publicado entre agosto de 1829 e agosto de 1831, contou ainda com a colaboração de Marcos Pinto Soares Vaz Preto, José Liberato Freire de Carvalho ${ }^{4}$ e José da Silva Carvalho e teve o particular apoio do marquês de Palmela. A Aurora foi um periódico que surgiu no seguimento do término da publicação do Paquete de Portugal e foi publicado entre dezembro de 1831 e outubro de 1832 . Teve a colaboração de Marcos Pinto Soares Vaz Preto, Cândido José Xavier, D. Luís do Rego Barreto e barão de Rendufe (Tengarrinha 2013: 453-455).

Vários periódicos mostraram-se contrários a D. Pedro e ao que consideravam ser o caráter demasiado moderado da Carta Constitucional. O primeiro a inserir-se nesta corrente foi $O$ Pelourinho, redigido por José Pinto Rebelo Carvalho entre 1831 e 1832. Este periódico, publicado de forma semiclandestina, foi considerado o mais violento da fação liberal, existindo divergências quanto ao seu local de produção ${ }^{5}$. Também contra D. Pedro surgiu, entre março e junho de 1832, O Português Constitucional em Londres, da autoria de Paulo Midosi. Este jornal considerava que a regência que estava a ser feita pelo ex-imperador do Brasil ia contra o estabelecido na Carta Constitucional. Ainda na oposição a D. Pedro surgiram O Perguntador, redigido anonimamente em Londres entre 1832 e 1834, e Notícias de Portugal, também de caráter anónimo e publicado, possivelmente, em 1833 (Tengarrinha 2013: 455-456).

Diversos periódicos procuraram afastar-se do conflito existente as duas fações liberais e apelavam à conciliação entre os exilados portugueses. Inseriram-se nesta linha $O$ Chaveco Liberal, redigido por José Ferreira Borges, Almeida Garrett e Paulo Midosi e publicado entre setembro e dezembro de 1829, e O Palinuro, escrito pelo mesmo Ferreira Borges entre agosto e setembro de 1830. O caráter conciliatório deste último periódico encontra-se expresso no seguinte apelo do seu redator: "Somos irmãos todos. Uma só pátria é nosso mais comum: vós jurastes defendê-la, não assassiná-la. Esse

4 Poucos meses mais tarde, tendo em conta a orientação política do jornal para uma linha de claro apoio a D. Pedro IV, José Liberato abandonou a sua redação e mostrou-se mais favorável a Saldanha do que a Palmela.

5 José Tengarrinha considera que foi redigido em Londres (Tengarrinha 2013: 453), ao passo que Isabel Nobre Vargues e Luís Reis Torgal apontam que foi editado em França (Vargues 1993-1994: $83)$. 
monstro, que a tem em ferros, é o inimigo que temos a combater. Às armas, soldados portugueses" ${ }^{6}$.

A produção jornalística dos exilados portugueses, à semelhança da dos de outras nacionalidades, foi menos intensa em França do que em Inglaterra, fruto da maior liberdade de expressão de que gozavam neste último país. Ainda assim, são de ressalvar quatro publicações, que trouxeram consigo a novidade, relativamente aos periódicos que eram redigidos em Inglaterra, de dois deles serem dedicados a temas não políticos e incluírem artigos de caráter mais científico.

Salientam-se, na categoria dos periódicos não políticos publicados em França, A Abelha ou Coleção de Conhecimentos os mais Agradáveis, Instrutivos, Necessários e Úteis [... Extraídos dos Jornais Científicos e Literários de Toda a Europa e das Obras dos Melhores Escritores, redigido por Francisco Ladislau Álvares de Andrade em 1830, e Anais das Ciências e das Artes Dedicados aos que Falam a Língua Portuguesa em Ambos os Hemisférios, publicado entre janeiro e julho de 1827 por José Diogo Mascarenhas Neto. No contexto político foram redigidos dois periódicos em França que se declaravam opositores de D. Pedro e da Regência na ilha Terceira. Foram eles Le Courier des Émigrés Portugais, editado já na segunda metade de 1831, e O Independente, escrito, possivelmente, entre 1831 e 1833 (Tengarrinha 2013: 456-457).

Esta intensa atividade jornalística que os exilados portugueses desenvolveram no estrangeiro comprova o nível de intelectualidade da elite que se encontrava exilada, na medida em que, para além de dominarem a língua portuguesa, tinham também de possuir bons conhecimentos de línguas estrangeiras, nomeadamente de inglês e de francês, não só para se manterem a par das notícias que eram relatadas nos jornais dos países onde se encontravam exilados, muitas das quais foram também usadas nos seus próprios periódicos, traduzidas para português, como para se movimentarem e contactarem com os habitantes dos lugares onde tinham sido acolhidos.

Tal como fizeram os emigrados espanhóis, que escreveram e publicaram livros um pouco por todos os lugares onde residiram no exílio, com especial destaque para Londres (Simal 2012: 363) ${ }^{7}$, também os exilados portugueses colocaram as suas capacidades intelectuais ao serviço de outros tipos de produção escrita que não o jornalismo, quer se tratassem de obras originais, quer fossem traduções de livros com os quais iam tendo contacto.

\footnotetext{
O Palinuro, 4, 20 de agosto de 1830, p. 31.

Todo o cap. 8 desta obra (Simal 2012: 359-414) é dedicado à produção escrita desenvolvida pelos emigrados espanhóis no exílio, tanto jornalística como literária, pelo que se constitui de suma importância para conhecer essa dimensão do exílio liberal espanhol.
} 
No caso das traduções, por exigência dos editores, os exilados encontravam-se dependentes pelo facto de terem de traduzir obras com as quais não se identificavam totalmente ou que não correspondiam às suas preferências literárias. Desta forma, muitas vezes as obras que eram alvo de tradução careciam de atualidade, ou seja, não eram as obras mais recentes e não se encontravam diretamente relacionadas com o momento político que se estava a atravessar (Santos 1985: 113).

Paris constituiu o principal local a partir do qual se efetuaram várias traduções, tanto de obras escritas em inglês como em francês, ao longo de todo o período da emigração liberal portuguesa. As traduções elaboradas pelos exilados portugueses em França eram maioritariamente traduções de romances e novelas, alguns dos quais da autoria de renomados autores internacionais. Assim, salienta-se a tradução de La Reine Fantasque, de Rousseau, de A ciência do bom homem Ricardo ou meios de fazer fortuna, de Benjamim Franklin, e de $O$ templo de Cnido, de Montesquieu. Os exilados liberais portugueses procederam também à elaboração de várias gramáticas, sobretudo em 1831, como as desenvolvidas por Francisco Solano Constâncio e por António Pereira de Figueiredo (Ramos 1972: 69-85).

Em sentido oposto, observa-se que se em Londres a produção jornalística foi bastante mais intensa do que em Paris, o mesmo não se verificou ao nível das traduções efetuadas pelos exilados. Neste sentido, importa destacar uma tradução feita por Rodrigo da Fonseca Magalhães. Em 1830, Rodrigo da Fonseca traduziu o trabalho do economista escocês John Ramsay McCulloch, Principles of Political Economy, tendo dedicado a tradução ao seu amigo José Balbino de Barbosa e Araújo, $1^{\circ}$ visconde de Telheiras (McCulloch 1830).

Segundo consta da dedicatória feita por Rodrigo da Fonseca, esta tradução destinava-se a ser utilizada pelos alunos do clube hispano-lusitano, instalado em Londres. Este clube foi fundado no decorrer da emigração liberal portuguesa em Inglaterra, em 1828, e é exemplificativo do estreito contacto que existiu entre os exilados portugueses e espanhóis em Londres, uma vez que o mesmo foi estabelecido com o objetivo de serem criadas as condições que possibilitassem a restauração do liberalismo, quer fosse através da união dos dois reinos ibéricos, quer fosse mediante a constituição de uma monarquia dual, chefiada por D. Pedro IV. Esta ideia de o pai de D. Maria poder vir a governar toda a Península Ibérica esteve bastante presente entre os constitucionais espanhóis desde a altura da outorga da Carta Constitucional portuguesa, em 1826 (Brancato 1995: 96).

Este trabalho de Rodrigo da Fonseca é ilustrativo da diferença que existia ao nível das traduções efetuadas pelos exilados nos dois grandes centros da 
emigração liberal já indicados. Ao passo que em França as traduções giravam, sobretudo, em torno de novelas e romances, ou seja, obras que tinham um caráter mais quotidiano e que podiam ser lidas por toda a população mais letrada, as traduções realizadas em Inglaterra, de que serve de exemplo a elaborada por Rodrigo da Fonseca, pareciam apresentar um caráter mais prático e singular, destinando-se particularmente a um grupo específico de intelectuais, consoante o tema de que tratassem.

Exemplificativo da ideia de que Londres, ao contrário de Paris, foi um local onde se assistiu a uma publicação mais intensa de obras originais por parte dos exilados portugueses é o caso de Almeida Garrett. Este, chegado a Inglaterra em junho de 1828 na companhia de Luísa Midosi, dedicou grande parte da sua estadia no país à produção literária, para além de ter colaborado em vários periódicos liberais aí publicados. Assim, de entre os principais trabalhos literários de Almeida Garrett no exílio há a salientar Memórias de João Córadinho, Adozinda, Bernal-Francês, Lírica de João Mínimo, Das leis penais, Ilva, Magriço e os Doze de Inglaterra e Infante Santo, A Lealdade em Triunfo ou a Vitória da Terceira, Da Educação, Portugal na Balança da Europa e O Elogio Fúnebre de Carlos Infante de Lacerda, Barão de Sobroso (Sousa 1999: 87-94). Estas publicações de Garrett no exílio não ficaram confinadas a um só estilo e abrangeram diferentes tipos de texto, desde a poesia até ao romance, passando por obras de caráter político. Esta situação demonstra a versatilidade do escritor romântico português, contrapondo com outros intelectuais no exílio, que se prenderam apenas a um género de escrita ou que se limitaram à atividade jornalística.

A um nível mais político, em 1829, Garrett dedicou-se ainda à tradução das intervenções feitas sobre a questão portuguesa por Lord Holland no Parlamento britânico, a 19 de junho desse ano. Nestas declarações, o político britânico, comprovando o seu caráter liberal, criticou e condenou os excessos e os abusos levados a cabo por D. Miguel e pelos absolutistas portugueses (Sousa 2011: 124).

Era possível observar que Almeida Garrett, já nesta altura, gozava de uma certa influência e notoriedade em Londres. Exemplo desta situação é o facto de o escritor romântico ser consideravelmente referido pelos académicos britânicos. Garrett foi consultado e referido por Kinsey no trabalho Brief Review of Literary History of Portugal e viu vários excertos da obra Adozinda serem traduzidos por John Adamson (Santos 1985: 116).

A produção intelectual desenvolvida pelos exilados no estrangeiro encontra-se diretamente relacionada e fortemente dependente dos contactos sociais que estes estabeleceram e da aprendizagem cultural que levaram a cabo durante esse período. 
Apesar de o exílio lhes ter sido imposto, fruto da vigência em Portugal de um regime contrário às suas convicções e ideologias, os exilados portugueses aproveitaram essa experiência para desenvolver contactos com novas realidades e culturas, mostrando-se bastante atentos às inovações que foram ocorrendo ao longo deste período, um pouco por toda a Europa, em vários domínios.

Desta forma, o exílio constituiu-se também como um lugar de formação e de aprendizagem, desenvolvidas através da leitura de obras estrangeiras, da frequência de bibliotecas e gabinetes de leitura, da assistência a cursos, da comparência em espetáculos e do contacto direto e quotidiano com os habitantes dos países de acolhimento, realizado através da presença em bailes e convívios sociais organizados pela elite europeia da época (Santos 1985: 113).

Um dos emigrados que mais se destacou neste âmbito foi António Bernardino Pereira do Lago, brigadeiro do corpo de engenheiros. Ao deixar as questões políticas para segundo plano, procurou dar mais ênfase às dimensões social e cultural que o exílio proporcionou. Como afirmava o próprio,

durante a minha emigração, desejando conhecer o caráter, costumes, governo, obras e estabelecimentos de diferentes povos, viajei na Inglaterra, na França e na Bélgica, adquirindo assim o que podia para minha particular instrução $[\ldots]$ fui sempre notando e escrevendo o que via e observava (Lago 1834: 4).

Sobre Inglaterra, e particularmente sobre Londres, Pereira do Lago considerava que era a terra da ciência, da caridade, do desenvolvimento industrial e rodoviário, da comodidade, da limpeza, da magnanimidade, da segurança e da liberdade, sendo esta última a qualidade mais apreciada pelos exilados portugueses refugiados naquele país.

À semelhança do que viria a fazer nos outros lugares por onde passaria no exílio, também em Inglaterra Pereira do Lago desenvolveu uma acentuada atividade cultural. Esta passou pela frequência de clubes, um dos quais era uma associação de liberais, a que terá acesso através de contactos políticos, pela frequência da London Institution, graças aos contactos que tinha com Freire Marreco, também ele emigrado em Londres. Ali teve a oportunidade de se familiarizar com os gabinetes de Física e Química e com as aulas de Ciências Sociais (Santos 1985: 114).

Relativamente a França, especialmente sobre a sua capital, o grande destaque feito por Pereira do Lago vai no sentido de este ser um local que tinha muito a dar em termos culturais, algo que também se verificava no 
caso londrino. No entanto, a maior diferença residia no facto de essa aprendizagem cultural poder ser feita de forma menos dispendiosa em França, em detrimento de Inglaterra.

São vários os espaços públicos franceses referidos por este exilado português como sendo lugares onde os estrangeiros se podiam engrandecer culturalmente e desfrutar do desenvolvimento da civilização francesa, nomeadamente os bailes públicos realizados aos domingos, os jardins iluminados, os teatros, as galerias de pintura e de antiguidade, os gabinetes de história natural, as livrarias e os bazares (Lago 1834: 235-237).

Os exilados portugueses, aproveitando o facto de não poderem regressar a Portugal, experienciaram os atrativos «civilizacionais» que estas capitais europeias propiciavam, constituindo esta a grande e principal vantagem de se encontrarem exilados, a que acrescia o facto de poderem contactar com uma sociedade e uma cultura percebidas como mais evoluídas do que as portuguesas.

Contrapondo a realidade britânica e a realidade francesa, Pereira do Lago não tinha dúvidas em afirmar que o acolhimento e o tratamento que eram providenciados aos estrangeiros, entre os quais se incluíam os exilados políticos, eram bastante mais calorosos e amistosos em França do que em Inglaterra (Lago 1834: 128).

Outras atividades desenvolvidas por Pereira do Lago no domínio cultural prenderam-se com a frequência de algumas sessões particulares no Instituto Real de França e com visitas à Escola Politécnica de Paris e ao Conservatório das Artes. A realização de várias destas atividades tornou-se possível devido aos contactos pessoais que Pereira do Lago estabeleceu no exílio, alguns por intermédio de indivíduos já seus conhecidos. Estes contubérnios revelaram-se de extrema importância para os exilados liberais, uma vez que permitiram a sua inserção numa sociedade que lhes era estranha.

Assim, Pereira do Lago, à semelhança do que fizeram outras centenas de emigrados portugueses, na sua senda de se instruir culturalmente, contactou de perto com figuras de maior ou menor relevo dos países por onde foi passando.

Em Inglaterra, o brigadeiro português teve oportunidade de contactar com o Doutor Blaker, autor de um método de ensino inovador na altura. Este método consistia na aprendizagem do alfabeto associando letras e imagens e na aprendizagem das operações básicas de matemática recorrendo a uma espécie de ábaco (Lago 1834: 16-17). Em Bruxelas, António Bernardino teve contacto com uma sociedade dirigida para o culto de flores, designada Sociedade de Flora, que conheceu após conviver com o seu secretário, Van-Den-Corput (Lago 1834: 270). 
No entanto, parece ter sido em França que Pereira do Lago desenvolveu com maior intensidade os contactos sociais, o que poderá ser indicativo do maior pendor cultural desta nação. Com efeito, a frequência de algumas sessões do Instituto Real de França foi-lhe possível graças ao convívio que desenvolveu com o seu secretário, o Barão de Ferrouier. Em Paris contactou também com o Doutor Alard, com Benjamim Constant, pensador e político francês, e com uma das principais personalidades francesas da época, com a qual vários outros exilados portugueses também conviveram, marquês de Lafayette.

O papel de Lafayette foi fundamental para o desenvolvimento das sociabilidades por parte dos exilados de várias nacionalidades em França, uma vez que eram constantes os convívios sociais organizados por sua iniciativa, fomentando o contacto e a amizade entre os seus frequentadores. Este ambiente foi experienciado por Pereira do Lago, visto que "foi pelo favor de Mr. Lafayette que eu poderei dizer-te alguma coisa das companhias em Paris, porque assisti às suas animadas e interessantes partidas (soirées) que eram às terças-feiras" (Lago 1834: 243). Para o brigadeiro português, Lafayette era um dos indivíduos que mais havia pugnado a favor da causa da liberdade não só de França, como da de outros países, que na altura lutavam pelo liberalismo, como Portugal e Espanha, sendo um declarado amante da sua pátria e da liberdade.

Semelhante opinião tem Palmela, que também conviveu com o general francês, assim como Saldanha e D. Pedro IV, como se pode observar pelo que nos deixou relatado o diplomata português nas suas Memórias, referindo-se a uma tentativa de reconciliação entre ele próprio e Saldanha, organizada pelo pai de D. Maria: "O general Lafayette, como patriarca do liberalismo, fez-nos uma espécie de homilia no mesmo sentido” (Memórias 2011:237).

De facto, Lafayette foi uma das personalidades com quem os exilados portugueses mais contactaram em Paris. Também o marquês de Fronteira revela que conviveu de forma bastante próxima com o general francês:

Não fomos só nós que nos relacionámos com intimidade com o general Lafayette - foram todos os nossos correligionários apresentáveis. O ser emigrado e mesmo revolucionário era uma grande qualidade para ser introduzido à presença do ilustre general (Ventura 2000: 28) ${ }^{8}$.

Houve outra figura em França, para além de Lafayette, com quem os emigrados portugueses tiveram um contacto mais próximo, Benjamim Constant.

8 Corresponde a uma citação de uma passagem das Memórias do marquês de Fronteira. 
Com esta personalidade francesa relacionaram-se, entre outros, Agostinho José Freire e Manuel Gonçalves de Miranda, residentes em Paris, e também Palmela (Bron 2013: 506).

Também Almeida Garrett desenvolveu importantes contactos sociais e relacionou-se de perto com importantes nomes da sociedade britânica da primeira metade de Oitocentos. É bastante provável que Garrett tenha frequentado um dos mais importantes centros políticos, sociais e literários da Inglaterra do século XIX, a casa de Lord Holland. Os encontros sociais organizados por Lord Holland eram frequentados por destacadas figuras liberais britânicas, como Byron, Scott, Lyndock, Melbourne e Mackintosh, contudo encontravam-se também abertos à presença de diplomatas estrangeiros e de exilados liberais. Entre os comparecentes portugueses contavam-se importantes nomes, como Palmela, marquês do Funchal, Cristóvão Pedro de Morais Sarmento, Luís António de Abreu e Lima, visconde de Itabaiana e, provavelmente, Almeida Garrett (Sousa 1999: 90).

O marquês de Palmela também estabeleceu contactos bastante próximos com outras importantes personalidades liberais britânicas, tais como Lord Palmerston, Lord Brougham e Sir James Mackintosh, que contribuíram para que a causa liberal portuguesa adquirisse uma dimensão internacional assinalável. A vida social de Palmela no exílio também ficou marcada pela frequência assídua do salão da princesa de Lieven, dos bailes organizados na embaixada da Áustria e dos encontros que tinham lugar no Traveller's Club. Outros exilados também estabeleceram diversos contactos sociais em Londres, como foram os casos de José da Silva Carvalho e de José Ferreira Borges, que se relacionaram com alguns radicais britânicos, como John Bowring e Edward Blaquière, e ainda com emigrados de outras nacionalidades, nomeadamente com o espanhol Arguelles (Bron 2013: 502-505). Foi, precisamente, graças à amizade com este exilado que Silva Carvalho teve a oportunidade de frequentar a casa de Lord Holland.

A acentuada presença de exilados portugueses nos encontros providenciados por Lord Holland está diretamente relacionada com o facto de o político britânico ser um distinto simpatizante da causa liberal portuguesa, tendo, inclusive, viajado por Portugal na altura das invasões francesas ${ }^{9}$. Outro fator que poderá ter facilitado o acesso de Garrett à casa de Lord Holland, bem como de outros exilados da classe média portuguesa, prende-se com

9 Lord e Lady Holland, acompanhados pelo médico e político John Allen, viajaram por Portugal entre finais de 1808 e inícios de 1809 e deixaram vários diários da viagem pelo país. Estes relatos encontram-se traduzidos e compilados em Sousa 2011. 
a sua pertença à Maçonaria, sociedade em que o anfitrião destes encontros também terá estado inserido.

Para além destes contactos sociais com a elite política e diplomática, Almeida Garrett também se relacionou com vários escritores britânicos, nomeadamente com Robert Southey, John Adamson, William Morgan Kinsey e, provavelmente, James Sheridan Knowles, travando amizade com estas e com outras individualidades, como os Hadleys, Lady Paget, Caroline Elizabeth Sarah Norton, Mister Goodeen e Richard Hebber. A relação entre Garrett e estes dois últimos explica-se pelo facto de o escritor português ser um frequentador assíduo das suas livrarias portuguesas. Era também atividade recorrente em Garrett as visitas ao Museu Real de Londres, espaços onde terá produzido alguns dos seus mais importantes textos (Sousa 1999: 87-92).

Vários dos escritores com que Garrett conviveu em Londres durante o exílio também se relacionaram com outras importantes figuras liberais portuguesas, nomeadamente com Palmela. Foram os casos de John Adamson, que inclusive dedicou o livro Lusitania Illustrata: Notices on the History, Antiquities, Literature of Portugal ao diplomata português, e de Miss Norton, tendo sido precisamente graças a este contacto que a poetisa britânica terá conhecido Almeida Garrett.

O escritor português afirmaria mais tarde que muitas recordações do período da emigração liberal eram de saudade (Garrett 1848: 14), possivelmente referindo-se a alguns dos encontros sociais e culturais que desenvolveu no exílio. Este testemunho de Garrett demonstra-nos que o exílio liberal, não obstante todas as dificuldades, também proporcionou bons momentos aos emigrados, o que os levou a recordar esses tempos, por vezes, com saudade e nostalgia.

Para além de Garrett e de Pereira do Lago, vários outros exilados portugueses investiram na sua aprendizagem cultural e na sua preparação enquanto homens do liberalismo fora de Portugal, tendo alguns, inclusive, completado a sua formação no estrangeiro. Foi o caso de José Pinto Rebelo de Carvalho, que estudou Ciências Físicas e Naturais na Universidade de Sorbonne, em França, e doutorou-se em Medicina na Universidade de Lovaina, na Bélgica. Por seu turno, José Silvestre Ribeiro, também ele emigrado em França e participante na expedição liberal de D. Pedro, desenvolveu um acentuado contacto com a educação francesa. Durante o seu exílio frequentou diversas aulas, nomeadamente as de História, lecionadas por François Guizot, as de Filosofia, ministradas por Victor Cousin, e as de História Literária, dadas por Abel-François Villemain (Santos 1979: 96), convivências que terão influenciado o seu pensamento futuro nos domínios social e cultural. 
Esta influência não era apenas visível na ação que os países de acolhimento exerciam sobre os exilados (embora, neste caso, tenha sido bastante mais evidente), visto que estes foram também responsáveis pelo desenvolvimento de contactos bilaterais no exílio. Para além de assimilarem uma nova cultura, que depois difundiam quando regressavam ao país de origem, os emigrados também davam a conhecer a sua cultura no país que os acolhia, levando os seus habitantes a simpatizar com ela e com a causa que defendiam, como se verificou nos casos de Lord Holland, em Inglaterra, e do general Lafayette, em França.

Enriquecendo o exílio liberal do ponto de vista cultural e social, acresce que os emigrados portugueses tiveram a oportunidade de conviver não só com a cultura do país que os abrigou, como também com a de outros países que chegava até eles através do contacto com exilados de outras nacionalidades, nomeadamente espanhóis e italianos. Este facto conferiu uma dimensão internacional ao fenómeno do exílio político deste período, não se circunscrevendo apenas às relações entre indivíduos de um qualquer país de origem e os cidadãos não estrangeiros residentes num determinado país de acolhimento. Os exilados portugueses, tal como os de outras nacionalidades, tornaram-se, assim, sujeitos cosmopolitas ao superarem a divisão geopolítica característica de todos os Estados, quer por intermédio da estadia efetiva em países estrangeiros, quer através de toda uma panóplia de produção cultural elaborada, ou ainda por meio dos contactos sociais estabelecidos, pelo que se pode afirmar que estes homens e mulheres acabavam por ser «cidadãos» não só de um, mas de vários países.

\section{Conclusão}

O exílio político liberal português, que se iniciou em 1828 e que terminou, para a maioria dos seus intervenientes, em 1832, revestiu-se de uma série de dimensões - política, cultural, social e intelectual - que o assemelharam à experiência vivida por cidadãos de outras nacionalidades, nomeadamente por espanhóis e por italianos.

Os exilados liberais procuraram retirar o melhor que essa experiência lhes podia providenciar e, neste sentido, aproveitaram o facto de estarem obrigados a viver fora do seu país natal para se engrandecerem intelectual e culturalmente, procurando acompanhar o desenvolvimento que ia tendo lugar nesses países, com o objetivo de poderem aplicar futuramente essas inovações em Portugal. 
Assim, muitos emigrados dedicaram parte do seu tempo no estrangeiro a frequentar importantes lugares culturais, transformando, desta forma, o exílio também num local de aprendizagem. Museus, escolas e bibliotecas eram lugares a que os exilados iam com frequência, destacando-se neste contexto Almeida Garrett e António Bernardino Pereira do Lago, que com estas ações contribuíram para transformar o seu exílio numa experiência menos penosa.

Para esta transformação contribuíram também os contactos sociais estabelecidos pelos exilados no estrangeiro, que permitiram inserir os liberais portugueses numa sociedade liberal internacional que vinha sendo construída desde os primeiros exílios políticos europeus do século XIX e na qual se destacavam eminentes personalidades europeias.

Estas atividades de caráter social e cultural desenvolvidas pelos exilados permitem afirmar que estes indivíduos foram agentes intelectuais e culturais bilaterais que contribuíram não só para que a sua cultura fosse conhecida no estrangeiro, como também para que a cultura estrangeira não passasse incógnita nos países de origem.

A observação e o contacto direto com as realidades de países europeus considerados mais evoluídos, que permitiram a conceção de ideias e de reformas a aplicar futuramente nos seus próprios países, foram outros dois importantes aspetos que caracterizaram os exílios liberais de Oitocentos e que tiveram efeitos práticos à medida que o regime liberal se ia implantando na Europa, tal como refere Maurizio Isabella para o exílio italiano (Isabella 2006: 514).

A experiência do exílio liberal de 1828-1832, mais do que qualquer outra, ficaria presente na vida dos que nela participaram até ao fim dos seus dias. Esta situação foi visível quer através das políticas que muitos exilados desenvolveram após 1834 no domínio cultural, e também governativo, quer através de algumas decisões que vários exilados tomaram, após o regresso a Portugal, no domínio pessoal. Neste sentido, há a destacar as decisões tomadas por duas importantes figuras liberais, Rodrigo da Fonseca e Mouzinho da Silveira, ao nível da educação dos filhos. Ambos os políticos optaram por enviar os respetivos descendentes para estudar no estrangeiro, o primeiro para Inglaterra e o segundo para França. Esta decisão reflete não só a ligação com que os exilados ficaram relativamente aos países que os abrigara anos antes, como também é elucidativa do seu gosto e preferência pelo ensino estrangeiro.

Tanto pelos contactos pessoais e institucionais estabelecidos pelos emigrados no exílio, como pela própria atenção que a causa constitucional portuguesa despertou nos países de acolhimento, particularmente nos locais 
onde os liberais se encontravam refugiados, o exílio português de 1828-1832 inseriu-se numa dimensão transnacional. Assim, é correto afirmar que os exilados portugueses também se encontraram inseridos na sociedade liberal internacional que os exílios levados a cabo por cidadãos de diversos países lograram criar.

O exílio liberal apresentou-se como um fenómeno bastante amplo que comportou uma forte dimensão internacional, não ficando exclusivamente circunscrito aos países de origem e de acolhimento, mas incluindo indivíduos de diversas nacionalidades, que contactaram entre si e contribuíram para o engrandecimento cultural e intelectual da Europa de Oitocentos.

\section{Bibliografia}

Bron, Grégoire (2013). Révolution et nation entre le Portugal et l'Italie: les relations politiques luso-italiennes des Lumières à l'internationale libérale de 1830. Tese de doutoramento. Vol. 2. Paris: ISCTE-IUL/École Pratique des Hautes Études.

Bonifácio, Maria de Fátima (2005). D. Maria II. Lisboa: Círculo de Leitores.

Brancato, Braz A. Aquino (1995). "Exilados espanhóis em busca de um rei constitucional”. Revista de Estudos Ibero-Americanos, 11. Faltam as páginas

Faria, Fábio Alexandre (2015). Circulações internacionais e Liberalismo. O exílio liberal português, 1828-1832. Lisboa: ISCTE (dissertação de mestrado policopiada).

Ferrão, António (1940). Reinado de D. Miguel: o Cerco do Porto (1832-1833). Lisboa: Publicações da Comissão de História Militar.

Garrett, Almeida (1848). Memória histórica da excelentíssima Duquesa de Palmela, D. Eugénia Francisca Xavier Telles da Gama. Lisboa: Imprensa Nacional.

Isabella, Maurizio (2006). "Exile and nationalism: the case of Risorgimento", European History Quarterly, 36 (4), 493-520.

Lago, António Bernardino Pereira do (1834). Cinco anos de emigração na Inglaterra, na Bélgica e na França, Lisboa: Imprensa Nacional.

Maia, Joaquim José da Silva (1841). História da Revolução do Porto em maio de 1828 e dos emigrados portugueses pela Espanha, Inglaterra, França e Bélgica. Rio de Janeiro: Tipografia Universal de Laemmert.

McCulloch, Ramsay (1830). Princípios de Economia Política. Trad. Rodrigo da Fonseca Magalhães. Londres: s. n.

Nemésio, Vitorino (1946). Exilados 1828-1832. História sentimental e política do liberalismo na emigração. Lisboa: Bertrand.

Palmela, Duque de (2011). Memórias do Duque de Palmela. Transcrição, prefácio e edição de Maria de Fátima Bonifácio. Lisboa: D. Quixote. 
Pinheiro, Magda (1996). Passos Manuel: o patriota e o seu tempo. Matosinhos: Afrontamento.

Ramos, Vítor (1972). A edição de língua portuguesa em França (1800-1850). Paris: Fundação Calouste Gulbenkian/ Centro Cultural Português.

Santos, Maria Lourdes Costa Lima dos (1985). Intelectuais portugueses na primeira metade de Oitocentos. Lisboa: Editorial Presença.

Santos, Maria Lourdes Costa Lima dos (1979). "Sobre os intelectuais portugueses no século XIX (do Vintismo à Regeneração)”, Análise Social, 15 (57), 69-115.

Simal, Juan Luis (2012). Emigrados. España y el exilio internacional, 1814-1834. Madrid: Centro de Estudios Políticos y Constitucionales.

Soriano, Luz (1883). História da Guerra Civil e do estabelecimento do governo parlamentar em Portugal compreendendo história diplomática militar e política deste reino desde 1777 até 1834. Terceira Época. Tomo 3. Parte 1. Lisboa: Imprensa Nacional.

Sousa, José Baptista de (1999). Almeida Garrett and Anglo-Portuguese cultural interaction, 1800-1850. Buckingham: University of Buckingham.

Sousa, José Baptista de (2011). Três diários de viagem em Portugal em 1808-1809. Lord e Lady Holland e Dr. John Allen. Casal de Cambra: Caleidoscópio.

Tengarrinha, José (2013). Nova história da imprensa portuguesa: das origens a 1865. Lisboa: Temas e Debates / Círculo de Leitores.

Vargues, Isabel Nobre e Torgal, Luís Reis (1993-1994). "Da revolução à contrarrevolução: vintismo, cartismo, absolutismo. O exílio político”, in José Mattoso (dir.), História de Portugal. Vol. 5. Lisboa: Círculo de Leitores, 65-87.

Ventura, António (2001). O exílio, os Açores e o cerco do Porto. D. Luís de Sousa Coutinho, Primeiro Marquês de Sta Iria, nas Guerras Liberais. Lisboa: Colibri.

Viana, António (1891). José da Silva Carvalho e o seu tempo. Vol. 1. Lisboa: Imprensa Nacional. 